\title{
Pulmonary Metastasectomy for Colorectal Cancer: Recent Reports Prompt a Review of the Available Evidence
}

\author{
Tom Treasure
}

Published online: 27 August 2014

(C) The Author(s) 2014. This article is published with open access at Springerlink.com

\begin{abstract}
Pulmonary metastasectomy for colorectal cancer is commonplace surgery, but the practice has grown on the basis of follow-up studies. These studies base their conclusion on the effectiveness of metastasectomy on the survival rates at 5 years of very highly selected patients. Three publications in the last year, a registry study, a meta-analysis and a randomised controlled trial of monitoring and early detection of cancer recurrence, prompted a review of the evidence. A critical examination of the evidence suggests that much of the apparent benefit may be due to selection of patients most likely to survive on the basis of well-known prognostic features, explicitly stated in the clinical record. Clinicians also assess their patients over time and do not offer surgery to those with faster progression. Such clinical judgements are of their nature often subtle and undocumented and thus cannot be retrieved from the clinical record. Although some patients may have long survival following pulmonary metastasectomy, and indeed their survival might be believed to be due to resection of pulmonary metastases, how many patients must be operated on to find these survivors? What is the number 'needed to treat'? It may be that of the patients having metastasectomy, for the greater proportion it does not materially alter their survival. A randomised controlled trial to resolve this uncertainty is in progress. The Pulmonary Metastasectomy in Colorectal Cancer (PulMiCC) trial is recruiting in Britain and Europe.
\end{abstract}

Keywords Colorectal cancer · Pulmonary metastasectomy · Carcinoembryonic antigen $\cdot$ Randomised controlled trials

\footnotetext{
T. Treasure $(\bowtie)$

Clinical Operational Research Unit, University College London, London WC1H 0BT, UK

e-mail: tom.treasure@gmail.com
}

\section{Introduction}

After potentially curative surgery for colorectal cancer, a policy of monitoring patients for asymptomatic recurrence is the standard of care $[1,2]$. Detection of recurrence is accomplished by measurement of carcinoembryonic antigen (CEA) and imaging with whole-body CT. This permits early detection of liver and or lung metastasis so that they can be evaluated for resection with intention to cure.

In 2007, the present author, who was receiving an increasing number of referrals to perform surgery for which there was no good evidence, challenged the effectiveness of pulmonary metastasectomy [3]. At about the same time, the European Society of Thoracic Surgeons (ESTS) opened its Lung Metastasectomy Project. When the Working Group reported in 2010, its leaders concluded 'the level of evidence to support current practice is too low to set firm recommendations to the members of ESTS. In the absence of a randomized controlled trial looking at the effectiveness of pulmonary metastasectomy on survival and quality of life, it is unlikely that the current practice will ever be influenced.'

This led to the Pulmonary Metastasectomy in Colorectal Cancer (PulMiCC) randomised controlled trial (RCT), now recruiting in Britain and Europe [4].

Three articles published within the last year underline in different ways the continuing and now pressing need for better evidence.

1. A systematic review of 25 studies published from 2000 to 2011 provides a meta-analysis of 2,925 patients who had pulmonary metastasectomy. The three well-established prognostic factors (more than one metastasis; an interval since primary resection of under 2-3 years; elevated CEA level) each approximately double the likelihood of early progression of disseminated disease after pulmonary metastasectomy $[5 \cdot \bullet]$. 
2. A population-based study of 543 patients, estimated to include about $60 \%$ of patients having pulmonary metastasectomy in Spain in a 2-year period from 2008 to 2010 , provides the first prospective study of practice [6*•]. Of these patients, $45 \%$ had multiple metastases, half had intervals of under 28 months and CEA level was elevated in $46 \%$. Many of these patients are therefore in the categories where the disease will progress irrespective of the metastasectomy.

3. An RCT involving 1,202 patients, the Follow-up After Colorectal Surgery (FACS) trial, found that intensive CEA and/or CT monitoring does detect metastatic cancer earlier than minimum follow-up, but the ensuing surgery did not result in any increased survival compared with that of patients in whom the metastatic disease remained undiscovered $[7 \bullet \bullet]$.

Wide acceptance that metastasectomy is effective in improving survival is based on numerous follow-up studies of highly selected patients. Randomised trials, control data and intention-to-treat analysis are lacking. An analysis of the how oncologists and surgeons arrived at their belief in the effectiveness of metastasectomy is the subject of this review.

\section{The Evidence for Pulmonary Metastasectomy in Colorectal Cancer}

There must now be over 100 follow-up studies, and they are still being submitted for publication. Amongst them there have been numerous multivariate analyses, including the landmark report of the International Registry of Lung Metastases [8]. There were three systematic reviews of pulmonary metastasectomy in colorectal cancer between 2007 and 2010 [9-11]. They are mutually consistent in their findings and are consistent with the most recent systematic review and metaanalysis reported in 2013.

In the meta-analysis, four factors were associated with shorter survival time after lung metastasectomy:

1. For patients with multiple lung metastases compared with a solitary metastasis, there was a hazard ratio (HR) of 2.04 [95 \% confidence interval (CI) 1.72-2.41]. Having more than a solitary metastasis doubles the likelihood of dying within 5 years.

2. Elevated prethoracotomy CEA level nearly doubles the likelihood of dying within 5 years (HR 1.91; $95 \%$ CI $1.57-2.32)$.

3. A 'disease-free' interval shorter than $2-3$ years between the primary operation and lung metastasectomy increases by about $60 \%$ the likelihood of dying within 5 years. (HR $1.59,95 \%$ CI $1.27-1.98)$.
4. Positive hilar and/or mediastinal lymph nodes also increase the likelihood of dying within 5 years by about $60 \%$ (HR 1.65, $95 \%$ CI 1.35-2.02).

No doubt aware of the potential for confusion, the Journal of Thoracic Oncology published a biostatistics primer for 'what clinicians ought to know' setting out the difference between prognostic and predictive factors: 'A prognostic factor is a variable that is assessed before starting any treatment; based on the value of this factor, the clinician can expect that a patient may have a better or worse clinical outcome (such as survival or response), regardless of what treatment the patient receives' [12].

It is important to remember that the first three factors are general prognostic factors, as is the third if the information is available before the metastasectomy [12].

It is impressive that these factors remain so powerful in the analysis of Gonzalez et al. [6••] because these have been well known for many years and operated-on patients were highly selected in the full knowledge of these factors. For them to emerge from an analysis with these HRs suggests that they are commonly overridden, as they were in the Spanish study [6••]. The authors of the meta-analysis, in their discussion, take the view that 'as long as a R0 resection is feasible, it seems currently unfair to deny surgery for those patients with two to four lesions', which reflects current beliefs in practice rather than being a conclusion that can be derived from the data [5••].

The fourth factor, the evidence of further dissemination from the lung metastasis to hilar and mediastinal nodes, is in these series usually a pathology finding because it would be unlikely and indeed irresponsible to knowingly operate on such patients. Metastasectomy is likely to be ineffective if patients have already further dissemination via the pulmonary lymphatics. The operation is doomed to fail in its objective to achieve R0 resection. Although it has been proposed that mediastinoscopy should precede pulmonary metastasectomy [13], we cannot know how many patients have mediastinal staging investigations because reports are always of patients who have had metastasectomy, and they do not tell us anything of the selection process.

Many studies go as far as to exclude patients who did not have histological confirmation of R0 resection [9, 10], thus further defeating any attempt to understand the outcomes on the basis of 'intention to treat', which is the information that should be put to patients when metastasectomy is being discussed with them. This illustrates one of the many pitfalls in the custom and practice of surgical follow-up studies as a means of reporting results of surgery and the impossibility of drawing reliable inferences from them [14].

Amongst the systematic reviews was a quantitative synthesis of 3,504 patients in 51 studies reported from 1971 to 2007 [11]. This revealed that that although the practice had grown, the case mix had been remarkably consistent over about four 
decades. In round figures, $60 \%$ of metastasectomy operations were for a solitary metastases, the interval averaged 36 months and $60 \%$ of patients had died within 5 years.

\section{Pulmonary Metastasectomy as Palliation}

There are few data on symptoms in any of these follow-up studies. [11]. Most patients having pulmonary metastasectomy are asymptomatic with respect to colorectal cancer. Occasionally, a pulmonary metastasis may cause symptoms (cough, haemoptysis, pain, etc.), and then surgery is assessed on an individualised basis.

At the terminal phase of the disease, there is not usually a pulmonary component to the symptoms or mode of death which might have been prevented by surgery. The policy of seeking out and resecting metastases is therefore not palliative in any sense.

\section{Selection or Surgery as the Determinant of Survival}

Reporting a small comparative study of pulmonary metastasectomy in 1980, Åberg et al. [15] wrote: 'It has been assumed, implied, or claimed that the 5-year survival without operation is nil. Control material is, however, lacking.'

Both sentences remain true 34 years later: it is widely believed that any 5-year survivors after pulmonary metastasectomy can thank the operation for their survival, but there are no control data. The best estimates of the degree of selection in the Spanish study [6*0] is that these are fewer than $5 \%$ of metastatic colorectal cancer patients, and estimates from Italian and Japanese studies indicate that the rates may be around $2-3 \%$, but the appropriate denominator is hard determine.

The assumption that survival at 5 years, were it not for lung metastasectomy, approaches zero is false. Data from the Thames Cancer Registry show that for patients with metastases at presentation (stage 4 in its terminology), the 5 and 10year survival rates were $10 \%$ and $5 \%$, respectively. We can consider the implications of these data in selection. We have known for years the characteristic of patients who have longer survival after metastasectomy. Clinicians caring for these patients have had, in addition, ample opportunity to review imaging to look at the number of metastases and their appearance and growth over time. So patients in follow-up studies were not only selected on the basis of the explicit criteria retrievable from the records but were further selected in full knowledge of their progression over time. This is probably the most powerful determinant of whether they will be alive some years later, and it might well be that the selected minority of patients will contain the natural survivors. A selection of 100 of 1,000 patients might include the 50 destined to live longer, and the resulting $50 \%$ survival is thus easily explained. We cannot capture this process from follow-up studies, and we must surely realise that the gap between survival without and with lung metastasectomy is not the difference between 0 and $50 \%$.

It should also be remembered that the process of selection has as its precondition that the patient must have survived to the time point of being considered for metastasectomy and therefore includes immortal time bias [16-18]. This is particularly true if, for example, responsiveness to chemotherapy is included in selection, and is particularly illustrated by apparently favourable results of second and third metastasectomy. There is a large conditional component of having already survived to the time point for a patient to be included in the cohorts having repeated metastasectomy.

The Thames Cancer Registry data were used to model what might have been the 5-year survival rates for patients in two large follow-up studies $[19,20]$. Survival curves were constructed for registry patients with a similar mix of cancer stages at registration and who remained alive for a period similar to the 'disease-free interval' in the published followup studies. The two 5-year survival rates were similar [21]. For more readily accessible accounts of this study, see the subsequent articles in which it is used [22, 23] (Table 1).

How can this be? From their recollections, clinicians defend their practice in the belief that formerly no such patients survived beyond 1 year or so and that now they see long-term survivors. It would not be the first time that the clinical impressions of committed and dedicated clinicians are not supported by evidence when they are put to a fair test [24]. Patients are selected for surgery on the basis of many factors, including the trajectory of their clinical state over a period, a feature that is not captured in surgical follow-up studies. The authors rely on the limited information recorded at a point in time when the decision was taken to perform metastasectomy. Back at the time of selection, the rate of progression is evident to clinicians, and those patients progressing are unlikely to appear in the operating theatre.

\section{How the Literature and the Belief in It Grew}

In the course of our studies of pulmonary metastasectomy, we became aware of the fascinating method of citation network analysis [25]. Greenberg [25] proposed that 'citation can be used to generate information cascades resulting in unfounded authority of claims'.

The citation lists of the 51 follow-up studies used in the quantitative synthesis [11] were used to analyse the nature of the evidence on which those authors themselves had relied in writing up their follow-up studies [26].

What we discovered was frenzy of mutual citation amongst authors with shared beliefs. (Fig. 1). We confirmed Greenberg's 
Table 1 Reported and modelled 2-year survival

\begin{tabular}{lllll}
\hline Authors & Date & Patients & Reported 5-year survival rate (\%) & Modelled 5-year survival rate (\%) \\
\hline McCormack et al. [19] & 1992 & 144 & $40(32-48)$ & 55 \\
Okumura et al.[20] & 1996 & 159 & $41(33-48)$ & 50 \\
\hline
\end{tabular}

A mathematical modelling study [21] in which Thames Cancer Registry survival data were used to construct survival analysis for groups of patients with a Dukes stage similar to that of patients in the surgical follow-up studies and still alive at 36 months, which was the average interval from primary to metastasectomy operation to exclude patients who had not survived long enough to have become candidates for pulmonary metastasectomy

${ }^{a}$ The $95 \%$ confidence interval is given in parentheses

statement that 'unfounded authority was established by citation bias against papers that refuted or weakened the belief; amplification, the marked expansion of the belief system by papers presenting no data addressing it; and forms of invention such as the conversion of hypothesis into fact through citation alone.'

The article by Åberg et al. [15] formally challenging the belief in metastasectomy reporting the only, albeit small, comparative study was cited twice. A case report buried within a 1944 'state of the art' lecture to the Boston Medical Society concerning progress in thoracic surgery [27] was cited by 14 of 51 of the index papers, and is the thirteenth most frequent of 334 cited papers. The article by Åberg et al. is directly relevant, and would show up in any search including the word 'metastasectomy'. The article by Blalock [27] has no relevance to the practice and can only have been passed on from author to author; it would not have been found in a literature search. There is no clue in the title, and the tenuous connection with practice would take some perseverance to discover if indeed the article had been read at all. The cascade effect is 'like rolling a snowball: it gets bigger and bigger - but it is just more snow' [26].

The practice of monitoring patients by means of their CEA level grew in the 1970s and 1980s, and was the basis of an RCT to determine if the earlier detection that it allowed, before the presence of symptoms, would result in better survival. The study recruited patients from 1982 to 1993. There was no benefit, but instead a small excess of deaths in those randomised to have CEA monitoring prompted second-look surgery (91 of 108 versus 88 of 108; difference $2.8 \%$ ) [28]. The reporting of the results of the trial lapsed in 1994, perhaps perceived to have been overtaken by events. As part of the initiative to restore invisible and abandoned trials [29, 30], the full results have been published [31]. The FACS trial asked the same question and returned the same answer in 2014. For 901 patients randomised to have CEA monitoring, CT or both, the mortality was $18.2 \%$, whereas for those having symptom-prompted investigations and clinical follow-up, the mortality was $15.9 \%$, a difference of $2.3 \%$, similar to that found in 1994 favouring patients spared unavailing second-look surgery (Table 2).
Fig. 1 This graphic is from a network analysis in which nodes 1-51 are the follow-up studies of lung metastasectomy for colorectal cancer in the quantitative synthesis, and the remaining nodes, to a total of 72 , are colorectal cancer studies which are cited. The article by Åberg et al. [15] questioning the effectiveness of lung metastasectomy is cited only twice, whereas there appears to be a feeding frenzy of mutual citation amongst the believers. (From Fiorentino et al. [26], with permission from Nature Publishing Group)

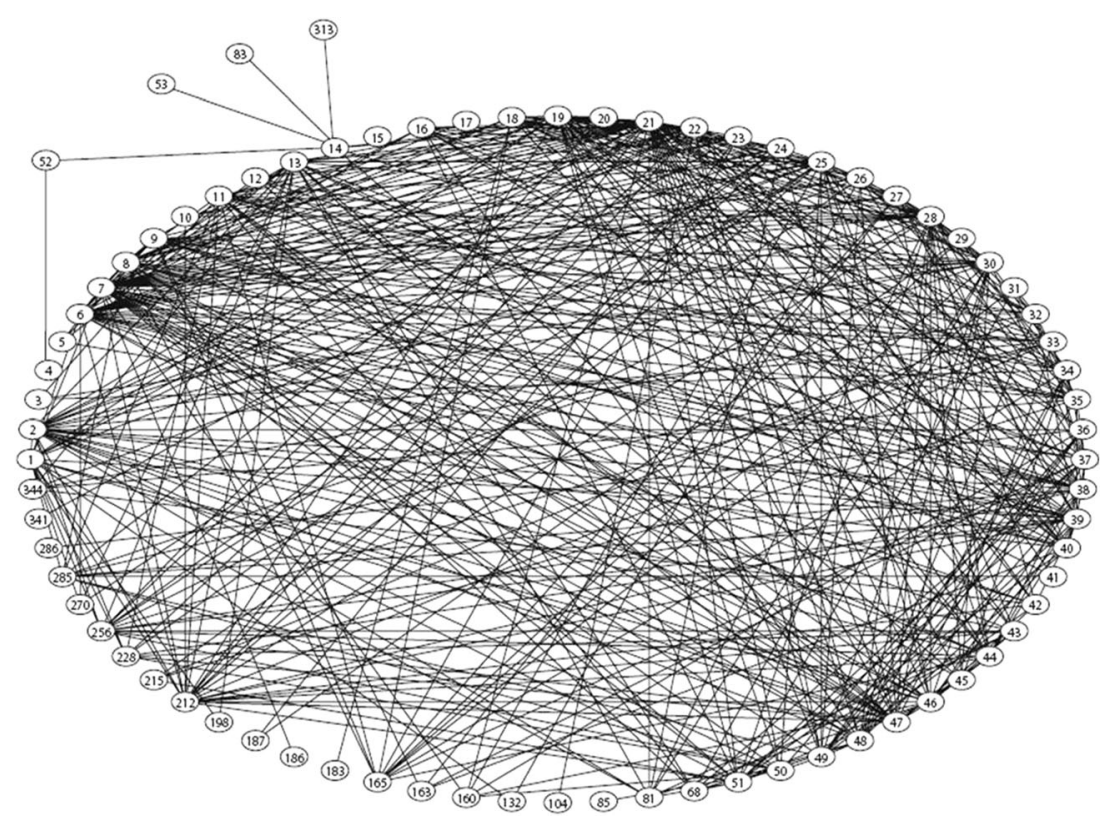


Table 2 How the evidence for metastasectomy for colorectal cancer was overtaken by events: the history of adoption of liver resection for colorectal metastasectomy is documented by Grunhagen et al. [37]

\begin{tabular}{|c|c|}
\hline Date & Publication \\
\hline 1954 & $\begin{array}{l}\text { Wangensteen et al. [38] advocated second-look surgery in } \\
\text { asymptomatic patients following colorectal cancer }\end{array}$ \\
\hline $1971-1978$ & $\begin{array}{l}\text { Resection of recurrent cancer after potentially curative } \\
\text { resection of colorectal cancer was believed sometimes } \\
\text { to lead to 'cure' [39-41] }\end{array}$ \\
\hline $1974-1980$ & $\begin{array}{l}\text { CEA monitoring was shown to detect asymptomatic } \\
\text { recurrence of colorectal cancer following surgery, with } \\
\text { the possibility of better results for second-look surgery } \\
\text { [42-46] }\end{array}$ \\
\hline 1981 & NIH consensus call for a trial of CEA monitoring [47] \\
\hline 1982 & The CEA Second-Look trial started recruiting [31] \\
\hline $1982-1989$ & $\begin{array}{l}\text { Hughes et al. [48-51] published registry results of liver } \\
\text { resection with increasing numbers }\end{array}$ \\
\hline $1990-1991$ & $\begin{array}{l}\text { Scheele et al. [52-54] published a growing institutional } \\
\text { cohort of liver resections }\end{array}$ \\
\hline 1992 & $\begin{array}{l}\text { McCormack et al. [19] published 10-year results of } \\
\text { pulmonary metastasectomy in colorectal cancer }\end{array}$ \\
\hline 1992 & $\begin{array}{l}\text { Rosen et al. [55] published the power calculation for a } \\
\text { randomised trial of liver resection. Claims for benefit } \\
\text { versus natural history were so far apart that, if correct, } \\
36 \text { patients would have been sufficient to prove it }\end{array}$ \\
\hline 1994 & CEA Second-Look Trial results available $[28,56]$ \\
\hline 1994 & $\begin{array}{l}\text { Stangl et al. [57] wrote 'benefit ... has been clearly } \\
\text { demonstrated' }\end{array}$ \\
\hline 1994 & $\begin{array}{l}\text { Scheele et al. [58] wrote 'trials on ... effectiveness of } \\
\text { hepatic resection for metastatic colorectal cancer } \\
\text { [would be] not only obsolete but unethical' }\end{array}$ \\
\hline 1997 & $\begin{array}{l}\text { The International Registry of Lung Metastases reported } \\
\text { its analysis of prognostic factors for lung } \\
\text { metastasectomy [8] }\end{array}$ \\
\hline
\end{tabular}

$C E A$ carcinoembryonic antigen, $N I H$ National Institutes of Health

\section{Oligometastasis and Ablative Therapies}

Minimally invasive therapies such as radiofrequency ablation (RFA) and stereotactic radiotherapy can destroy tissues accurately and reliably without the need for open surgery. They have a very valuable role in treating symptomatic lesions where the evidence of effectiveness is basically the $\mathrm{N}$ of one trial. In comparison with surgery, they are proposed as an alternative to metastasectomy, being safer and less invasive. However, the arguments rest on a prior belief that surveillance and eradication of asymptomatic metastases improves survival, which has been shown not to be the case [7०0]. If we are unsure of the effectiveness of surgery in this regard, effectiveness of less invasive ablation must be tested in its own right. This has been done for colorectal liver metastases. There was no difference in survival between those patients who had and those patients who did not have RFA in this RCT [32•]. On the basis of the only RCT evidence available, RFA was thus ineffective in improving survival.
The oligometastatic state, a term coined by radiation therapists [33] and now in the argot of cancer teams and tumour boards, has shaky evidence. It is a concept without empirical evidence. The 'fewness' of metastases is no doubt a reflection of the biological nature of that individual's cancer: the more metastases, the more aggressive the cancer, and the converse is a necessary corollary. There is no suggestion that the distribution of the number of metastases is bimodal, which would be expected if the oligometastatic state were a pathological entity. It is no more than an arbitrary convention to give some identity to what is no more than a therapeutic opportunity [34]. To define a disease by the therapy available and that would be needed to treat it is perfectly reasonable and is standard, for example, in end stage renal disease $[35,36]$, but the treatment should still be proven to be effective.

\section{Conclusions}

We know that of all patients having pulmonary metastasectomy, most go on to die of their colorectal cancer. Of all patients with pulmonary metastases, only $2-3 \%$ have pulmonary metastasectomy, and of this highly select group, authors further select subsets in whom there were high 5-year survival rates. But how many are 'cured'? Or is it that this process of selection on selection simply identifies the minority with slowly progressing disease?

It is the view of the author that pulmonary metastasectomy is offered to patients without adequate evidence. There are many historical precedents for reversals in practice and belief. The PulMiCC RCT is in progress and will provide the first controlled data to guide future practice.

The PulMiCC trial design is based on the premise that of patients with lung-only or liver and lung metastases many will be not be offered metastasectomy. At the other end of the spectrum of adverse to favourable features are the patients that most teams will consider for metastasectomy. It follows that if there is a 'no' for some and 'yes' for others, there must be a transitional zone of uncertainty. It is only in that zone, and it varies between the more conservative and the more aggressive team, that randomisation is invited in the second stage of the recruitment process. However, all patients can be recruited into the first stage.

\section{Compliance with Ethics Guidelines}

Conflict of Interest Tom Treasure is chief investigator of the Pulmonary Metastectomy in Colorectal Cancer trial, but declares that he has no financial conflict of interest.

Human and Animal Rights and Informed Consent This article does not contain any studies with human or animal subjects performed by the author. 
Open AccessThis article is distributed under the terms of the Creative Commons Attribution License which permits any use, distribution, and reproduction in any medium, provided the original author(s) and the source are credited.

\section{References}

Papers of particular interest, published recently, have been highlighted as:

- Of importance

-. Of major importance

1. Guideline Development Group. Colorectal cancer: the diagnosis and management of colorectal cancer. London: National Institute for Health and Clinical Excellence; 2011. Available from: http:// guidance.nice.org.uk/CG131/Guidance/pdf/English. Accessed 7 Oct 2012.

2. Benson A et al. Colon cancer version 3.2014. Fort Washington: National Cancer Collaborative Network; 2014. http://www.ncen. org/professionals/physician_gls/pdf/colon.pdf.

3. Treasure T, Utley M, Hunt I. When professional opinion is not enough: surgical resection of pulmonary metastases. BMJ. 2007;334(7598):831-2.

4. Treasure T, Fallowfield L, Lees B, Farewell V. Pulmonary metastasectomy in colorectal cancer: the PulMiCC trial. Thorax. 2012;67(2):185-7.

5.• Gonzalez M, Poncet A, Combescure C, Robert J, Ris HB, Gervaz P. Risk factors for survival after lung metastasectomy in colorectal cancer patients: a systematic review and meta-analysis. Ann Surg Oncol. 2013;20(2):572-9. The authors used 15 published case series which had to include more than 40 patients, and tat were published from 2000 to 2011, to obtain pooled data on 2,925 patients. HRs for death within 5 years were 2.04 if there was more than one metastasis, 1.91 if there was an elevated prethoracotomy CEA level, 1.59 for an interval less than 3 years between the primary and secondary operations and 1.65 if there were positive hilar or mediastinal nodes.

$6 . •$ Embun R, Fiorentino F, Treasure T, Rivas JJ, Molins L. Pulmonary metastasectomy in colorectal cancer: a prospective study of demography and clinical characteristics of 543 patients in the Spanish colorectal metastasectomy registry (GECMP-CCR). BMJ Open. 2013;3(5). Data were collected prospectively from March 2008 to February 2010 from 32 Spanish units estimated to capture 60\% of the national practice. Of these patients, $55 \%$ had a solitary metastasis and 46\% had elevated CEA level, and the median interoperative interval was 28 months. There is a comparison with the HRs reported in Gonzalez et al. [5]

7.• Primrose JN, Perera R, Gray A, Rose P, Fuller A, Corkhill A, et al. Effect of 3 to 5 years of scheduled CEA and CT follow-up to detect recurrence of colorectal cancer: the FACS randomized clinical trial. JAMA. 2014;311(3):263-70. An RCT involving 1,202 subjects tested the effectiveness of intensive monitoring of patients by CEA level and/or CT following potentially curative colorectal cancer resection. Patients who had no scheduled monitoring other than a CT scan at 18 months $(n=301)$ had a death rate of $15.9 \%$ by $3-5$ years, whereas intensively monitored patients had a death rate of $18.2 \%\left(P=0.37, \chi^{2}\right.$ test $)$. After interim analysis, the trialists were told that they were very unlikely to ever show a difference in overall survival as the main outcome measure so they changed it to surgical treatment with curative intent.

8. Pastorino U, Buyse M, Friedel G, Ginsberg RJ, Girard P, Goldstraw $\mathrm{P}$, et al. Long-term results of lung metastasectomy: prognostic analyses based on 5206 cases. J Thorac Cardiovasc Surg. 1997:113:37-49.

9. Pfannschmidt J, Dienemann H, Hoffmann H. Surgical resection of pulmonary metastases from colorectal cancer: a systematic review of published series. Ann Thorac Surg. 2007;84(1):324-38.

10. Pfannschmidt J, Hoffmann H, Dienemann H. Reported outcome factors for pulmonary resection in metastatic colorectal cancer. J Thorac Oncol. 2010;5(6 Suppl 2):S172-8.

11. Fiorentino F, Hunt I, Teoh K, Treasure T, Utley M. Pulmonary metastasectomy in colorectal cancer: a systematic review and quantitative synthesis. J R Soc Med. 2010;103(2):60-6.

12. Simms L, Barraclough H, Govindan R. Biostatistics primer: what a clinician ought to know-prognostic and predictive factors. J Thorac Oncol. 2013;8(6):808-13.

13. Menon A, Milton R, Thorpe JA, Papagiannopoulos K. The value of video-assisted mediastinoscopy in pulmonary metastasectomy. Eur J Cardiothorac Surg. 2007;32(2):351-4.

14. Treasure T, Utley M. Statistics for the rest of us: ten traps for the unwary in surgical series: a case study in mesothelioma reports. J Thorac Cardiovasc Surg. 2007;133(6):1414-8.

15. Åberg T, Malmberg KÅ, Nilsson B, Nõu E. The effect of metastasectomy: fact or fiction? Ann Thorac Surg. 1980;30(4): 378-84.

16. Levesque LE, Hanley JA, Kezouh A, Suissa S. Problem of immortal time bias in cohort studies: example using statins for preventing progression of diabetes. BMJ. 2010;340:b5087.

17. Suissa S. Immortal time bias in pharmaco-epidemiology. Am J Epidemiol. 2008;167(4):492-9.

18. Suissa S. Immortal time bias in observational studies of drug effects. Pharmacoepidemiol Drug Saf. 2007;16(3):241-9.

19. McCormack PM, Burt ME, Bains MS, Martini N, Rusch VW, Ginsberg RJ. Lung resection for colorectal metastases. 10-year results. Arch Surg. 1992;127(12):1403-6.

20. Okumura S, Kondo H, Tsuboi M, Nakayama H, Asamura H, Tsuchiya R, et al. Pulmonary resection for metastatic colorectal cancer: experiences with 159 patients. J Thorac Cardiovasc Surg. 1996;112(4):867-74.

21. Utley M, Treasure T, Linklater K, Moller H. Better out than in? The resection of pulmonary metastases from colorectal tumours. In: Xie X, Lorca F, Marcon E, editors. Operations research for health care engineering: Proceedings of the 33rd International Conference on Operational Research Applied to Health Services. Saint-Etienne: Publications de l'Universitaire de Saint-Etienne; 2008. p. 493-500.

22. Utley M, Treasure T. Interpreting data from surgical follow-up studies: the role of modeling. J Thorac Oncol. 2010;5(6 Suppl 2): S200-2.

23. Fiorentino F, Treasure T. Pulmonary metastasectomy for colorectal cancer: making the case for a randomized controlled trial in the zone of uncertainty. J Thorac Cardiovasc Surg. 2013;146(4):748-52.

24. Fiorentino F, Treasure T. Pulmonary metastasectomy: are observational studies sufficient evidence for effectiveness? Ann Thorac Surg. 2013;96(4):1129-31.

25. Greenberg SA. How citation distortions create unfounded authority: analysis of a citation network. BMJ. 2009;339:b2680.

26. Fiorentino F, Vasilakis C, Treasure T. Clinical reports of pulmonary metastasectomy for colorectal cancer: a citation network analysis. Br J Cancer. 2011;104(7):1085-97.

27. Blalock A. Recent advances in surgery. N Engl J Med. 1944;231: 261-7.

28. Northover J, Houghton J, Lennon T. CEA to detect recurrence of colon cancer. JAMA. 1994;272(1):31.

29. Doshi P, Dickersin K, Healy D, Vedula SS, Jefferson T. Restoring invisible and abandoned trials: a call for people to publish the findings. BMJ. 2013;346:f2865. 
30. Loder E, Godlee F, Barbour V, Winker M. Restoring the integrity of the clinical trial evidence base. BMJ. 2013;346:f3601.

31. Treasure T, Monson K, Fiorentino F, Russell RCG. The CEA Second-Look Trial: a randomised controlled trial of carcinoembryonic antigen prompted re-operation for recurrent colorectal cancer. BMJ Open. 2014;4:e004385.

32. Ruers T, Punt C, van CF, Pierie JP, Borel-Rinkes I, Ledermann JA, et al. Radiofrequency ablation combined with systemic treatment versus systemic treatment alone in patients with non-resectable colorectal liver metastases: a randomized EORTC Intergroup phase II study (EORTC 40004). Ann Oncol 2012;23(10):2619-26. This is important for two reasons. One is that it is an RCT, which distinguishes it in the literature related to resection and ablation of metastases. The second is the sentence: 'The study shows that local tumour ablation by RFA in combination with systemic therapy results in an excellent survival, which however was also achieved in the control arm,' The finding of the study was there was no difference between the groups, so any treatment effect, excellent or otherwise, cannot be attributed to RFA.

33. Hellman S, Weichselbaum RR. Oligometastases. J Clin Oncol. 1995;13(1):8-10.

34. Treasure T. Oligometastatic cancer: an entity, a useful concept, or a therapeutic opportunity? J R Soc Med. 2012;105(6):242-6.

35. Peitzman SJ. From Bright's disease to end-stage renal failure. In: Rosenberg CE, Golden J, editors. Framing disease. Philadelphia: Rutgers; 1992. p. 3-19.

36. Rettig RA. Special treatment - the story of Medicare's ESRD entitlement. N Engl J Med. 2011;364(7):596-8.

37. Grunhagen D, Jones RP, Treasure T, Vasilakis C, Poston GJ. The history of adoption of hepatic resection for metastatic colorectal cancer: 1984-95. Crit Rev Oncol Hematol. 2013;86(3):222-31.

38. Wangensteen O, Lewis F, Arhelger S, Muller J, Maclean L. An interim report upon the second look procedure for cancer of the stomach, colon, and rectum and for limited intraperitoneal carcinosis. Surg Gynecol Obstet. 1954;99(3):257-67.

39. Polk Jr HC, Spratt Jr JS. Recurrent colorectal carcinoma: detection, treatment, and other considerations. Surgery. 1971;69(1):9-23.

40. Ellis H. Is a 'second look operation' justified in suspected recurrences after abdominal cancer surgery? Br J Surg. 1975;62(10):830-2.

41. Welch JP, Donaldson GA. Detection and treatment of recurrent cancer of the colon and rectum. Am J Surg. 1978;135(4):505-11.

42. Mach JP, Jaeger P, Bertholet MM, Ruegsegger CH, Loosli RM, Pettavel J. Detection of recurrence of large-bowel carcinoma by radioimmunoassay of circulating carcinoembryonic antigen (C.E.A.). Lancet. 1974;304(7880):535-40.

43. Mackay AM, Patel S, Carter S, Stevens U, Laurence DJ, Cooper $\mathrm{EH}$, et al. Role of serial plasma C.E.A. assays in detection of recurrent and metastatic colorectal carcinomas. Br Med J. 1974;4(5941):382-5.
44. Staab HJ, Anderer FA, Stumpf E, Fischer R. Carcinoembryonic antigen follow-up and selection of patients for second-look operation in management of gastrointestinal carcinoma. J Surg Oncol. 1978;10(3):273-82.

45. Nicholson JR, Aust JC. Rising carcinoembryonic antigen titers in colorectal carcinoma: an indication for the second-look procedure. Dis Colon Rectum. 1978;21(3):163-4.

46. Martin Jr EW, Cooperman M, Carey LC, Minton JP. Sixty secondlook procedures indicated primarily by rise in serial carcinoembryonic antigen. J Surg Res. 1980;28(5):389-94.

47. Goldenberg DM. Carcinoembryonic antigen: its role as a marker in the management of cancer. Summary of an NIH consensus statement. Br Med J (Clin Res Ed). 1981;282(6261):373-5.

48. Hughes ES, McConchie IH, McDermott FT, Johnson WR, Price $\mathrm{AB}$. Resection of lung metastases in large bowel cancer. Br J Surg. 1982;69(7):410-2.

49. Hughes KS, Simon R, Songhorabodi S, Adson MA, Ilstrup DM, Fortner JG, et al. Resection of the liver for colorectal carcinoma metastases: a multi-institutional study of patterns of recurrence. Surgery. 1986;100(2):278-84.

50. Registry of Hepatic Metastases. Resection of the liver for colorectal carcinoma metastases: a multi-institutional study of indications for resection. Surgery. 198;103(3):278-88

51. Hughes K, Scheele J, Sugarbaker PH. Surgery for colorectal cancer metastatic to the liver. Optimizing the results of treatment. Surg Clin North Am. 1989;69(2):339-59.

52. Scheele J, Stangl R, Altendorf-Hofmann A. Hepatic metastases from colorectal carcinoma: impact of surgical resection on the natural history. Br J Surg. 1990;77(11):1241-6.

53. Scheele J, Altendorf-Hofmann A, Stangl R, Gall FP. Pulmonary resection for metastatic colon and upper rectum cancer. Is it useful? Dis Colon Rectum. 1990;33(9):745-52.

54. Scheele J, Stangl R, Altendorf-Hofmann A, Gall FP. Indicators of prognosis after hepatic resection for colorectal secondaries. Surgery. 1991;110(1):13-29.

55. Rosen CB, Nagorney DM, Taswell HF, Helgeson SL, Ilstrup DM, Van Heerden JA, et al. Perioperative blood transfusion and determinants of survival after liver resection for metastatic colorectal carcinoma. Ann Surg. 1992;216(4):493-504.

56. Lennon T, Houghton J, Northover J. Post operative CEA monitoring and second-look surgery in colorectal cancer: trial results. Br J Cancer. 1994;70(Suppl xxii):16.

57. Stangl R, Altendorf-Hofmann A, Charnley RM, Scheele J. Factors influencing the natural history of colorectal liver metastases. Lancet. 1994;343(8910):1405-10.

58. Scheele J, Stang1 R, Altendorf-Hofmann A, Paul M. Resection of colorectal liver metastases. World J Surg. 1995;19(1):59-71. 